Gallagher, S. (in press). The shadow of the transcendendal: Social cognition in Merleau-Ponty and cognitive science. K. Novotny (ed.), Corporeity and Affectivity. Proceedings of the conference on Merleau-Ponty at 100, Prague 2007. Brill Publishers.

\title{
The shadow of the transcendental: Social cognition in Merleau-Ponty and cognitive science
}

\author{
Shaun Gallagher \\ Philosophy and Cognitive Sciences \\ Institute of Simulation and Training \\ University of Central Florida (USA) \\ and University of Hertfordshire (UK) \\ gallaghr@mail.ucf.edu
}

If anything can make plausible Merleau- Ponty's seemingly paradoxical thesis that human understanding necessarily tends to misunderstand itself, it is, surely, those two particularly rampant forms of logocentric objectivism that today go under the heading of Cognitive Science and Artificial Intelligence. ... In their search for the universal algorithm, they represent a kind of innate, genetically programmed disease of the human mind, or, at least, of modernist, Western logocentric consciousness. ${ }^{1}$

The author of this statement, Gary Madison, was quite familiar with Hubert Dreyfus's (1972) use of phenomenology in his critique of "good old fashioned artificial intelligence" (GOFAI) -- and of Merleau-Ponty's role in this. One can see some of the thinking behind this kind of critique in Merleau-Ponty's Structure of Behavior.

When one attempts, as I have in The Structure of Behavior, to trace out, on the basis of modern psychology and physiology, the relationships which obtain between the perceiving organism and its milieu one clearly finds that they are not those of an automatic machine which needs an outside agent to set off its pre-established mechanisms" (Merleau-Ponty 1967, 4).

Up until 1991, this had been the only game in town that had anything explicit to say about phenomenology and cognitive science. In 1991 two books changed that. The first, Dennett's Consciousness Explained was diametrically opposite to the position that Madison defends, and outlined a quick dismissal of the relevance of phenomenology. The second, however, by Francisco Varela, Evan Thompson, and Eleanor Rosch, The Embodied Mind was also diametrically opposite to Madison, but in the opposite direction to Dennett, in showing the relevance of Merleau-Ponty's phenomenological notion of embodiment for cognitive science.

Dennett's book was capitalizing on a new interest in consciousness that was emerging in cognitive science -- ironically, the very idea that motivated phenomenology, but that many "Continental philosophers" were then deconstructing and running away 
from as fast as possible. In Continental philosophy, phenomenology and the interest in consciousness was in decline at this time, except among a handful of staunch (or reactionary) defenders like Madison, who, in truth (as one might say), were more concerned to react against poststructuralism than to even consider cognitive science. Madison's pronouncement was not the result of a large analysis, but only a passing comment.

While Dennett was revitalizing GOFAI with injections of neurotransmitters, and placing his bets on distributed brain processes rather than phenomenology, Varela et al. had already bought into Dreyfus's critique, and were looking beyond the brain to a new incarnation of cognitive science where Merleau-Ponty's phenomenology would find an important place. In 1991, for a perspective that orients itself to Merleau-Ponty, things were not so simple as either Madison or Dennett thought.

\section{Paris (Royaumont) 1960}

Merleau-Ponty, in the 1940s, was engaged in an interdisciplinary study (neurology, developmental psychology, psychopathology) of embodied cognition oriented in a phenomenological perspective (anticipating what today we would call the third wave of cognitive science [see Gallagher and Varela 2003]). This was a project that he was still interested in up until the time of his death in 1961. Indeed, in 1960 he met with a group of analytic philosophers, including Ryle, Ayer, and Quine at a conference at Royaumont, outside of Paris. Ayer, in his comments on Ryle's presentation, seemed open to the legitimacy of phenomenology.

[I]t seems to me ... that one can legitimately pose some question about the whole ensemble of processes, of manners of being, of actions, of sensations, or of impressions that one cannot consider as objects - let us say - memory; in what does memory consist? Is it essential to reserve this notion to designate only those experiences that are our own? .... And it is not impossible that this is the genre of research that certain disciples of Husserl recommend, in which case their curiosity seems to me perfectly legitimate (Ayer, in Merleau-Ponty 1960, pp. 63-64).

Merleau-Ponty picked up just where Ayer left off:

I have also had the impression, while listening to Mr. Ryle, that what he was saying was not so strange to us [phenomenologists], and that the distance, if there is a distance, is one that he puts between us rather than one I find there. (Merleau-Ponty 1960, p. 64).

Ryle, for his part resists phenomenology. He also resists empirical science - his understanding of the latter given in the example of chemists working with test tube.

See here what comes to my mind when speaking of research of fact. Nothing very mysterious, as you see. But what matters is that the questions of fact of this order are not the province of philosophy. One will never say that so and so is a better philosopher than so and so 
because so and so knows facts of which the other is ignorant. (Ryle, in Merleau-Ponty 1960, 67).

His student, Dennett, would take issue with that view thirty years later. In 1961, however, one could identify four clear positions, the first one taken by the phenomenologist Herman Von Breda, who, as head of the Husserl archives, represented Husserl's position.

- To understand the mind we should appeal to pure phenomenology (Von Breda)

- To understand the mind we should pursue empirical science (Quine)

- To understand how we use the term 'mind' we should distance ourselves from both phenomenology and empirical science (Ryle)

- To understand the mind we need both phenomenology and empirical science (Merleau-Ponty)

One can still see these positions at work today. Patricia Churchland, for example, follows Quine: "philosophy at its best and properly conceived is continuous with the empirical sciences" (1986: 2). Dennett (who studied with both Quine and Ryle) champions empirical science as well. Both keep their distance from phenomenology. Dennett, curiously, bemoans the reception he received in Paris and Nice in 1985 and again in 1992. "The French Husserlians either were aghast or found me beneath notice, in spite of my attempt to convey my sense of my Husserlian heritage" (Dennett 1994), the latter apparently based on his work with Ryle, who read the phenomenologists. In more recent years, however, and especially in the empirical cognitive neurosciences, the resistance to phenomenology has decreased; and among at least a few phenomenologists, Dennett is noticed, even if without a lot of sympathy (see, e.g., Drummond 2007; Marbach 1993; 2007; Zahavi 2007).

I think it is clear that Merleau-Ponty has played a posthumous role in all of this. As phenomenology has worked its way into the cognitive sciences, in the various movements associated with embodied and situated cognition, enactive perception, and recent work on social cognition (see e.g., Gallagher 2005; Gallagher and Zahavi 2008; Noë 2004; Thompson 2007), the work of Merleau-Ponty has continued to remain central. Let me also mention that one inspiration for Gibson's (anti-representationalist) work was Merleau-Ponty. "I've been told by many people independently that Gibson handed out copies of the Phenomenology of Perception to his graduate students, and told everyone who asked that to understand what he was doing, one had to understand Merleau-Ponty" (Anthony Chemero, private correspondence).

\section{Intersubjectivity}

Rather than rehearsing more history, and rather than trying to set out every aspect of Merleau-Ponty's philosophy that seems relevant to contemporary debates -- about naturalism, or phenomenological methodology, or representationalism, or embodied cognition, or enactive perception, or language, etc. -- all themes that fit easily into contemporary cognitive science -- let me focus on one topic that I think has the potential to shift our perspectives in the same way that embodied-enactive approaches have shifted our perspectives and have redefined cognitive science -- the theme of intersubjectivity. 
Intersubjectivity, not in the sense of the problem of other minds, or theory of mind, or social cognition -- an important topic in its own right -- but (to borrow the phrase from Husserl, which Merleau-Ponty himself used) transcendental intersubjectivity. The problem of transcendental intersubjectivity is a problem that should concern cognitive scientists. To see precisely what the problem of is, first let's distinguish it from the problem of social cognition.

Back in Paris in 1960, Merleau-Ponty pressed Ryle about the importance of understanding how we understand others. What Ryle says about this in The Concept of Mind (1949) can be interpreted in simple behavioristic terms, or in terms that are quite similar to a long-standing phenomenological insight. Ryle rejects the Cartesian official doctrine: the minds of others are hidden away and inaccessible to us. We do not make "untestable inferences to any ghostly processes occurring in streams of consciousness which we are debarred from visiting" (1949, p. 51). That is, Ryle rejects what we today call "theory theory" (TT). He points out that if we had to depend on making inferences from a knowledge of psychological laws we would be led to the paradox that if someone actually knew these laws, they could never explain them to anyone else who also didn't already know them. Ryle also rejects what today is called simulation theory (ST), on much the same grounds as phenomenologists like Scheler and Merleau-Ponty rejected the argument from (inference by) analogy, showing that it would involve a fallacious inference: "the observed appearances and actions of people differ very markedly, so the imputation to them of inner processes closely matching [one's own or] one another would be actually contrary to the evidence" (1949, p. 54).

Perhaps Ryle's position on social cognition is one of the things that MerleauPonty thought was not so strange or distant from the phenomenologists, since he would also reject TT and ST - both of these approaches share assumptions that Merleau-Ponty would reject, namely:

1. The "problem of other minds" is framed in terms of the lack of access that we have to the other person's mental states - inference is necessary.

2. Our normal everyday stance toward the other person is a third-person, observational stance.

3. These mentalizing processes constitute our primary and pervasive way of understanding others.

Phenomenology rejects the Cartesian idea that other minds are hidden away and inaccessible; rather, we directly perceive the other person's intentions, emotions, and dispositions in their embodied behavior. No inference is necessary in most cases. Our normal everyday stance toward the other person is not third-person, detached observation; it is second-person interaction. We are not primarily spectators or observers of other people's actions; for the most part we are interacting with them on some project, or in some pre-defined relation. Our primary and pervasive way of understanding others does not involve mentalizing or mindreading; in fact, these are rare and specialized abilities that we develop only on the basis of a more embodied approach (see Gallagher 2005).

For Merleau-Ponty, our perception of others is interactional rather than observational -- the actions of others elicit the activation of our own motor systems. At a 
very basic level, in my perception of you, my motor system resonates with your actions. This view, of course, resonates very well with the contemporary neuroscience of mirror systems, but what is at stake here is precisely what Merleau-Ponty calls intercorporeity (1969, p. 141) - which (contra many neuroscientists) is not something that can be characterized as simulation. "The mirror arises upon the open circuit [that goes] from seeing body to visible body.... My own body's 'invisibility' can invest the other bodies I see" (Merleau-Ponty 1967, p. 168)

There are explicit arguments to be made against implicit versions of ST (Gallagher 2007), and there are alternative interpretations of mirror neuron studies that are perfectly consistent with Merleau-Ponty's view. All of this falls under the heading of social cognition -- it's the problem of how we come to understand others -- and there are currently large debates among TT, ST, and the more phenomenonlogically inspired work on interaction theory (IT), etc.

\section{Transcendental Subjectivity}

The problem of transcendental intersubjectivity (TI) is different. To see the problem of TI in Merleau-Ponty's terms, consider Samuel Todes's analysis in his Body and World (2001). Todes argues, from a phenomenological perspective, and not unlike MerleauPonty, that it is not possible to provide an account of our cognitive experience of the world without an account of the body's role in that experience. Todes offers a rich description of how we experience time and space in an embodied fashion; how within temporal and spatial frameworks objects appear constituted as objects; how perception and imagination are generated within the matrix of these non-conceptual worldly frameworks; and how the more abstract accomplishments of thinking and conceptualization are based on the fundamental motor and perceptual accomplishments of the body. Todes' primary aim is to give a phenomenological account of objectperception, and he explicitly sets aside questions about social cognition, or personperception, which, he admits, is likely a different kind of experience: "the way I know persons differs from the way I know objects" (2001, p. 2).

All issues in the social philosophy of the human body, all issues concerning our body's role in our knowledge of persons, are carefully avoided. ... The reader is thus forewarned that the analyses presented in this study are not of our normal experience in its full complexity .... for the purposes of this study of the human body as the material subject of the world, our experience is simplified by disregarding our experience of other human beings (2001, p. 1).

This is fair enough, but Todes goes further: he assumes that object perception can be analyzed without introducing any considerations about our interaction with others. Indeed, an analysis of social cognition, according to Todes, presupposes the analysis of object perception. On Todes' strategy, we would come to understand the fullness and complexity of human experience by first understanding how an isolated body, moving alone in the world, perceives non-living objects, and then adding to this an analysis of how others enter into the picture. The fact that "the way I know persons differs from the way I know objects," and the phenomenal dimension of social interaction that 
characterizes human existence at least from birth, on his view, have nothing to do with the way we perceive objects.

The concept of TI goes directly against this assumption. TI suggests that our experiences of the world -- the world of objects, the spatial-temporal world of events, sunsets and seascapes and mountain vistas that turn us on, fast cars, works of art, as well as ugly architecture and works of terror -- all of these are all under the influence of others. So, to provide an analysis of object perception without considering the way that intersubjectivity shapes that perception, is to remain with an abstraction.

There are a large number of examples of philosophical analyses that are philosophically autistic, in the sense that they don't even notice TI. I'll just mention Descartes, Kant, Locke, Hume. More surprising, however, there are more recent accounts that invoke Merleau-Ponty, but that nonetheless remain without reference to TI. Alva Noë (2004), for example, presents an excellent account of enactive perception -- but the world in which we act and perceive, although full of things, apparently is underpopulated by other people - although in his book there are plenty of first-person embodied perspectives to engage in a variety of pragmatic and epistemic pursuits. One nice example (a symptom of the problem): If we wanted to visit Prague Castle, how would we go about finding it? (see Noe 2004, p. 23)

- First strategy (traditional, representational): use a map, figure out where you are, map out a path, keep checking your progress against the map.

- Second strategy (enactive): you see the castle in the distance from where you are and you set out in that direction -- by trial and error you eventually get to the castle.

- A third strategy (entirely missing from Noë): ask our friend Ivan Havel for directions.

Throughout Noë's analysis, we find elements like central nervous systems, sensory organs, skin, muscles, limbs, movements, actions, physical and pragmatic situations to deal with -- his account is entirely embodied, emphatically embedded, and exhaustively enactive -- with requisite references to Merleau-Ponty. The point, however, is not simply that there is a scarcity of people (every now and then you do bump into an isolated embodied soul in the book). Rather, the point is that there is no consideration given to the role that others (and our social or intersubjective interactions with them) may play in the shaping of perceptual processes.

For Noë, "the key to [the enactive theory] is the idea that perception depends on the possession and exercise of a certain kind of practical knowledge" (2004, p. 33). The mind is "shaped by a complicated hierarchy of practical skills" (p. 31). If we ask, how do we get this practical know how, his answer is not unlike the answer provided by Todes -embodied practice and action. Consider, however, that we might actually get it from others -- watching them act, imitating them, interacting with them, communicating with them, entering into those intercorporeal resonant processes -- and doing this even before we know what we are doing -- from birth onwards.

Merleau-Ponty acknowledges this intersubjective shaping of experience, which, following Husserl, he calls transcendental intersubjectivity. The claim is that it is not just the body that shapes the mind, but that intersubjective processes, which are closely tied to 
our affective experience, shape the way that we perceive the world -- including our perception of others. This is a challenge for cognitive science -- in the same way that cognitive science needs to take embodiment into account, it also needs to take intersubjectivity into account -- as a "prenoetic" force that shapes our cognitive processes (Gallagher 2005).

How can the cognitive sciences approach this problem? Similar to MerleauPonty, by considering the evidence from developmental psychology, social neuroscience, and phenomenology. For example, in analyses that focus on the early experience of others, Colwyn Trevarthen (1979; Trevarthen and Hubley 1978) develops his concepts of primary and secondary intersubjectivity, which tell us not only about how the infant comes to understand others (the problem of social cognition) but how those others start to shape the infant's experiences in phenomena like joint attention and social referencing. The infant comes to perceive the world by seeing how others interact with the world. In developing the enactive approach to cognition found in Varela et al. (1991), and inspired by Merleau-Ponty, De Jaegher and Di Paolo (2007) refer to this as "participatory sensemaking" (see Gallagher 2009).

Whether this concept of participatory sense-making is the naturalized equivalent to something like Husserl's transcendental intersubjective constitution of the meaning and objectivity of the world, or whether the problem of transcendental intersubjectivity can be naturalized, is a controversial issue. In this regard, I would once again turn to MerleauPonty.

Now if the transcendental is intersubjectivity, how can the borders of the transcendental and the empirical help becoming indistinct? ... All of my facticity is reintegrated into subjectivity .... Thus the transcendental decends into history. (Merleau-Ponty 1967, p. 107).

Whatever one thinks about this issue, a cognitive science approach that enlists the resources of developmental psychology, social psychology, social neuroscience, phenomenology and philosophy of mind could certainly capture, at the very least, the empirical shadow of the transcendental.

\section{References}

De Jaegher, H., \& Di Paolo, E. 2007. Participatory sense-making: An enactive approach to social cognition. Phenomenology and the Cognitive Sciences, 6(4), pp. 485-507.

Dennett, D. 1991. Consciousness explained. New York: Little, Brown and Co.

Dennett, D.C. 1994. Tiptoeing past the covered wagons: A response to Carr, in Dennett and Carr Further Explained: an exchange, Emory Cognition Project, Report \#28, Department of Psychology, Emory University, Apr. 1994; and at http://cogprints.org/278/0/tiptoe.htm

Dreyfus, H. 1972. What Computers Can't Do: The Limits of Artificial Intelligence. Cambridge, MA: MIT Press.

Drummond, J. 2007. Phenomenology: Neither auto- nor hetero- be. Phenomenology and the Cognitive Sciences 6 (1-2): 57-74.

Churchland, P. S. 1986. Neurophilosophy. Cambridge, MA: MIT Press.

Gallagher, S. 2005. How the Body Shapes the Mind. Oxford: Oxford University Press. 
Gallagher, S. 2007. Simulation trouble. Social Neuroscience. 2 (3-4): 353-65.

Gallagher, S. 2009. Two problems of intersubjectivity. Journal of Consciousness Studies $16(6-8): 289-308$.

Gallagher, S. and Francisco Varela. 2003. Redrawing the map and resetting the time: Phenomenology and the cognitive sciences. Canadian Journal of Philosophy. Supplementary Volume 29: 93-132.

Gallagher, S. and Zahavi, D. 2008. The Phenomenological Mind. London: Routledge.

Madison, G. 1990. Merleau-Ponty et la déconstruction du logocentrisme. Laval théologique et philosophique, 46 (1): 65-79

Marbach, E. 1993. Mental Representation and Consciousness: Towards a Phenomenological Theory of Representation and Reference. Dordrecht: Kluwer Academic.

Marbach, E. 2007. No heterophenomenology without autophenomenology: Variations on a theme of mine. Phenomenology and the Cognitive Sciences 6 (1-2): 75-87.

Merleau-Ponty, M. 1960. Phenomenology and analytic philosophy. In Text and Dialogues. Ed. \& Trans. H. Silverman and J. Barry (59-72). Amherst, NY: Prometheus Books, 1992.

Merleau-Ponty, M. 1967. The Structure of Behaviour. Boston: Beacon Press.

Merleau-Ponty, M. 1969. The Visible and the Invisible. Evanston: Northwestern University Press.

Noë, A. 2004. Action in Perception. Cambridge: MIT Press.

Ryle, G. 1949. The Concept of Mind. New York: Barnes Noble.

Thompson, E. 2007. Mind in Life: Biology, Phenomenology, and the Sciences of Mind. Cambridge, MA: Harvard University Press.

Todes, S. 2001. Body and World. Cambridge: MIT Press.

Trevarthen, C. B. 1979. Communication and cooperation in early infancy: A description of primary intersubjectivity. In M. Bullowa (ed.), Before Speech. Cambridge: Cambridge University Press.

Trevarthen, C. and Hubley, P. 1978. Secondary intersubjectivity: Confidence, confiding and acts of meaning in the first year. In A. Lock (ed.), Action, Gesture and Symbol: The Emergence of Language (pp. 183-229). London: Academic Press.

Varela, F. Thompson, E., Rosch, E. 1991. The Embodied Mind. Cambridge, MA: MIT Press.

Zahavi, D. 2007. Killing the straw man: Dennett and phenomenology. Phenomenology and the Cognitive Sciences 6 (1-2): 21-43. 
Notes:

1 "Ce qui peut servir à rendre plus plausible la thèse apparemment paradoxale de Merleau-Ponty sur la tendance nécessaire de la compréhension humaine à se mécomprendre, ce sont assurément les deux formes particulièrement déchaînées de l'objectivisme logocentriste qui se nomment Cognitive Science et Artificial Intelligence. En effet, il serait difficile de trouver deux mécompréhensions plus complètes de la comprehension humaine. Dans leur recherche de l'algorithme universel, elles représentent une sorte de maladie génétique programmée dans l'esprit humain ou, au moins, dans la conscience moderniste occidentale logocentriste" (Madison 1990, p. 74). 